\title{
Ecological Hazards of MTBE Exposure: A Research Agenda
}

\author{
T. Carlsen \\ L. Hall \\ D. Rice
}

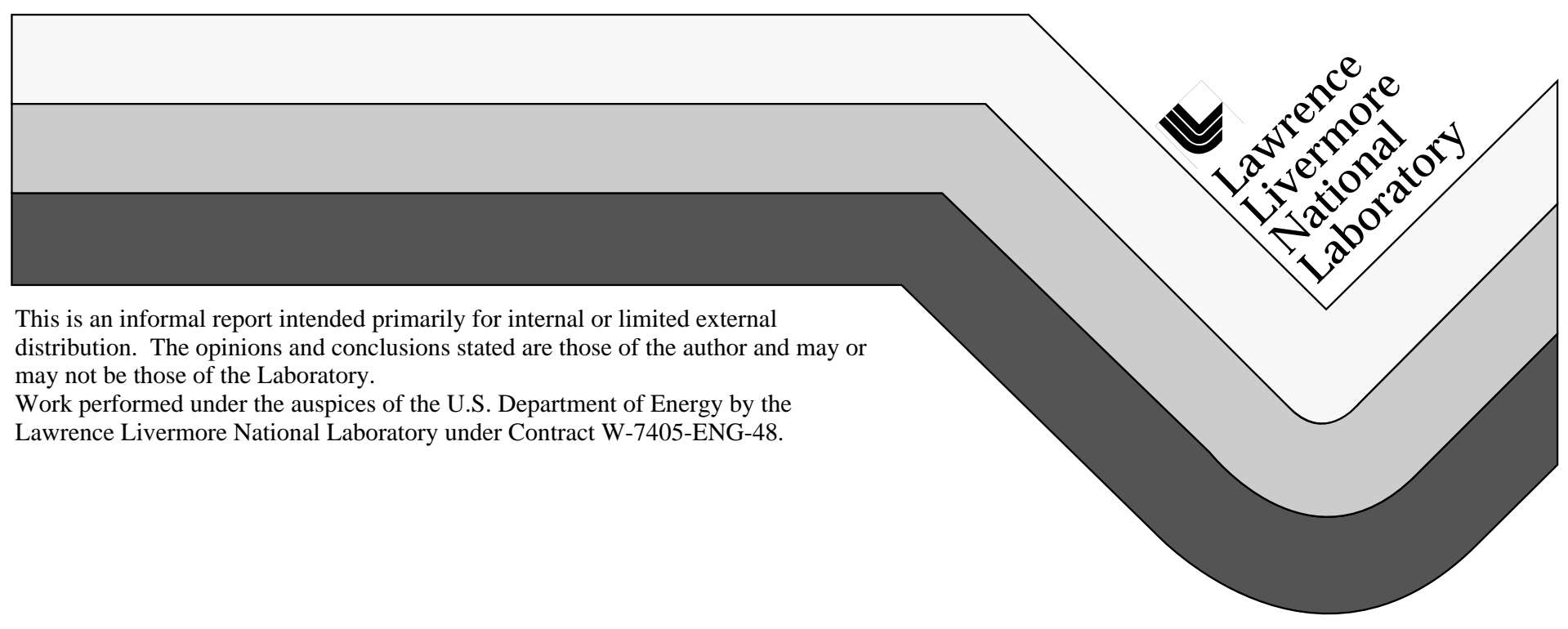




\section{DISCLAIMER}

This document was prepared as an account of work sponsored by an agency of the United States Government. Neither the United States Government nor the University of California nor any of their employees, makes any warranty, express or implied, or assumes any legal liability or responsibility for the accuracy, completeness, or usefulness of any information, apparatus, product, or process disclosed, or represents that its use would not infringe privately owned rights. Reference herein to any specific commercial product, process, or service by trade name, trademark, manufacturer, or otherwise, does not necessarily constitute or imply its endorsement, recommendation, or favoring by the United States Government or the University of California. The views and opinions of authors expressed herein do not necessarily state or reflect those of the United States Government or the University of California, and shall not be used for advertising or product endorsement purposes.

This report has been reproduced directly from the best available copy.

Available to DOE and DOE contractors from the Office of Scientific and Technical Information

P.O. Box 62, Oak Ridge, TN 37831

Prices available from (615) 576-8401, FTS 626-8401

Available to the public from the

National Technical Information Service

U.S. Department of Commerce 5285 Port Royal Rd.,

Springfield, VA 22161 


\section{Ecological Hazards of MTBE Exposure: A Research Agenda}

Tina Carlsen, Linda Hall and David Rice

Lawrence Livermore National Laboratory

\section{Introduction}

Fuel oxygenates are used in metropolitan areas across the United States in order to reduce the amount of carbon monoxide released into the atmosphere during the winter. The most commonly used fuel oxygenate is Methyl tert-butyl ether (MTBE) (OSTP 1996). Its widespread use has resulted in releases into the environment. To date there has been only minimal effort to investigate ecological impacts caused by exposure to concentrations of MTBE typically found in environmental media. Research into the potential for MTBE to adversely affect ecological receptors is essential. Acquisition of such baseline data is especially critical in light of continuing inputs and potential accumulation of MTBE in environmental media.

\section{Assessing Ecological Impacts}

Determining the potential for ecological damage as a consequence of chemical releases into the environment is recognized as a critical component of hazard assessment (Suter and Loar 1992, Carlsen 1996). Indeed, several federal statutes (such as CERCLA, RCRA and FIFRA), require the identification and mitigation of ecological impacts associated with chemical releases into the environment. As a result, a variety of methods are available to estimate the ecological hazard from chemical releases. These methods range from the qualitative to quantitative (Solomon 1996, USEPA 1992, Warren-Hicks et al. 1989). Most of these methods share some basic elements. Typically, an evaluation of the potential pathways in which ecological receptors can be exposed to the chemical is conducted. The groups of exposed organisms are identified and the probable level of exposure determined. Finally, the ecological significance (if any) of this exposure is identified. While this last step is the most crucial, it is often the most difficult. While demonstrating exposure of an ecological receptor to a chemical is clearly necessary, it is not sufficient to determine that an ecologically meaningful impact has occurred.

The exposure analysis will likely result in the identification of numerous species which could potentially be exposed to chemicals released into the environment. It is often necessary to group the biota into major ecological functional groups to simplify the initial exposure pathway analysis. Once the initial exposure pathway analysis is complete, specific groups of organisms may be selected for in-depth hazard assessment. Organisms selected for the detailed analysis are often considered "sentinel organisms" (Suter, et al., 1987, Grizzle, et al., 1988, Rice et al., 1994). When 
evaluating ecological exposure, it is necessary to identify or consider 1 ) the organisms that are actually or potentially exposed and the exposure level, 2) the significant routes of exposure, 3) the spatial and temporal scales of exposure, and 4) the geophysical, physical and chemical properties that could affect exposure.

To determine the ecological significance of exposure to a chemical, it is necessary to select ecological endpoints to be examined. Endpoints are characteristics of an ecological component (such as fish mortality) that may be affected by exposure to a stressor (Suter 1990, USEPA 1992). It is useful to distinguish between two types of endpoints, assessment endpoints and measurement endpoints. Assessment endpoints are explicit expressions of the actual environmental values that are to be protected (USEPA 1992, Warren-Hicks et al. 1989). Measurement endpoints are the measurable responses to a stressor that are related to the valued characteristics chosen as the assessment endpoint (Suter 1990). In some cases, measurement endpoints and assessment endpoints are equivalent.

Although there are a number of ways to specifically define ecological assessment endpoints, in general they should 1) be relevant to society, 2) have biological or ecological relevance, 3) have an unambiguous operational definition, 4) be measurable or predictable, 5) be susceptible to hazard, and 6) be logically related to the policy or remedial decisions. In the context of evaluating the ecological impacts of MTBE exposure, assessment endpoints should be environmental characteristics that if significantly affected would indicate the need for some type of action. This action may include reevaluating the current policy concerning MTBE use, and/or may point to a need to remediate environmental media containing MTBE.

If endangered species are not involved, plants and animals are typically not valued biologically as individuals, and therefore the assessment endpoints are usually related to entire populations or communities (Warren-Hicks et al. 1989, Moriarty 1983). An example of a populationbased assessment endpoint would be "change in the abundance of aquatic or amphibian populations". However, due to their rarity, individual members of endangered species are considered essential to the survival of the species. In this case assessment endpoints related to individuals are appropriate. "Increase in mortality or decrease in reproductive potential of individual San J oaquin kit fox" is an example of an appropriate assessment endpoint in this case.

As mentioned above, measurement endpoints are a quantitative expression of an observed or measured effect of a stressor that is related to the valued characteristic chosen as the assessment endpoint. Measurement endpoints should have specific characteristics, depending on the problem at hand. Most importantly, measurement endpoints should 1) correspond to or be predictive of an assessment endpoint, 2) be readily measured, 3) be appropriate for the scale of the problem, 4) be appropriate to 
the exposure pathway, 5) be appropriate to temporal dynamics, 6) have low natural variability, and 7) be diagnostic of the contaminant of interest.

Continuing with the two examples given for assessment endpoints, corresponding measurement endpoints might include "reduced number of fish eggs hatching" and "fewer pups per litter for individual San J oaquin kit fox". These measurement endpoints clearly relate to the assessment endpoints. However, such measurement endpoints can require maintaining large lab populations for a significant length of time or conducting lengthy field studies. Recent research has focused on identifying biochemical changes which are precursors to reduced reproductive success. Examples include binding affinity to estrogen receptors and induction of the mixed-function oxidase (MFO) enzyme system. However, care must be taken when using such biochemical measurement endpoints to show that they directly tie to the assessment endpoint.

\section{Potential Ecological Impacts of MTBE}

MTBE can be introduced into the environment during all phases of the petroleum fuel cycle (Squillace, et al., 1996). However, releases from point source spills and from dispersed atmospheric sources resulting from the use of oxygenated fuels likely comprise the major contribution of MTBE to the environment (OSTP 1996). Point source spills can result in MTBE in surface soil, surface water, subsurface soil and ground water. MTBE has been detected in storm-water samples at concentrations up to $8.7 \mu \mathrm{g} / \mathrm{L}$, and in surface water samples at ten California lakes used for drinking water, ranging from 1 to $25 \mu \mathrm{g} / \mathrm{L}$ and more recently at $88 \mu \mathrm{g} / \mathrm{L}$ in Lake Shasta, California. MTBE has been detected in ground water at concentrations up to $23 \mathrm{mg} / \mathrm{L}$ (OSTP 1996) and more recently in Santa Monica drinking water supply wells in excess of $500 \mu \mathrm{g} / \mathrm{L}$. Use of oxygenated fuels result primarily in atmospheric emissions of MTBE. Median concentrations of MTBE in ambient air range from 0.13 to $4.6 \mathrm{ppb} / \mathrm{v}$. These atmospheric emissions also contribute to surface water concentrations of MTBE through rain-out. There are very limited data on the concentrations and spatial and temporal distributions of MTBE in surface water, ground water and air (Delzer, et al., 1996; OSTP 1996; Squillace, et al., 1996), and no data has been found on surface or subsurface soil concentrations of MTBE. However, MTBE does not adsorb to soil organic matter very well, so retardation is minimal (Delzer, et al., 1996). This would suggest that MTBE soil concentrations would be close to zero (Davidson 1996).

Due to the large quantities in use (6.2 billion $\mathrm{kg}$ in 1994, OSTP 1996), MTBE has the potential to occur in most environmental media. As a result, there are a number of ecological receptors which could be exposed to MTBE. The presence of MTBE in surface water may result in exposures of aquatic life. Terrestrial biota may be exposed due to the presence of MTBE in surface water, soil and air. 
Marine biota may be exposed due to bulk tanker spills and sewage outfall releases and the potential for marine impacts is significant. MTBE is manufactured from methane derived from natural gas. Since natural gas supplies are limited in the United States (US), MTBE is produced outside the US and shipped in bulk to coastal US ports. The behavior, fate and impact of MTBE in the marine environment resulting from a tanker accident is unknown.

Potential environmental exposure pathways may include:

- Direct exposure to and ingestion of MTBE by marine, aquatic and terrestrial wildlife

- Uptake, accumulation, and transpiration of MTBE by marine, aquatic and terrestrial plants

- Inhalation of MTBE by terrestrial wildlife

In addition, any bioaccumulation or bioconcentration of MTBE could substantially increase the amount of MTBE plants and animals are exposed to beyond that indicated simply by MTBE concentrations in environmental media.

\section{Environmental Chemistry of MTBE in relation to Bioaccumulation/ Bioconcentration through the Food chain}

Environmental contaminants that pose a risk to biota are typically ubiquitous, persistent, and often have properties that favor bioaccumulation and transfer between species. MTBE is becoming a ubiquitous environmental contaminant, due to the magnitude of material released and to its persistence in the terrestrial environment. MTBE is notably resistant to degradation in soil and water; it does not sorb significantly to soils, and tends to move readily in surface and ground water (Squillace, et al., 1996). MTBE thus has the potential to migrate widely in the environment, and to come in contact with vulnerable organisms.

Although the majority of MTBE released is emitted into the atmosphere, MTBE's physical properties cause it to partition into, and remain in, water. Once in water, MTBE is relatively soluble (solubility $\sim 50,000 \mathrm{mg} / \mathrm{L}$ ), suggesting the potential for accumulation as inputs continue over time (OSTP 1996). MTBE is also moderately lipophilic (log octanol water partition coefficient, $\mathrm{K}_{\mathrm{ow}}$, of 1.2 ), a property which is generally predictive of a chemical's ability to accumulate in biota (OSTP 1996; Mackay 1991). However, no data exist which characterize MTBE's potential for bioaccumulation or bioconcentration in aquatic (or other) species, or which characterize MTBE's potential for transfer and/or bioconcentration through the food chain.

\section{Organisms Potentially Exposed to MTBE}




\section{Aquatic Organisms}

MTBE's chemical properties indicate that MTBE has the potential to accumulate in surface waters, and in the aquatic organisms which inhabit them. Thus, there is the possibility of uptake and accumulation of MTBE by aquatic organisms and in species that rely on them as a food source. Studies to characterize the tendency of MTBE to accumulate and concentrate in aquatic organisms should be initiated. If these studies indicate that MTBE can accumulate in biota, subsequent studies of food chain transfer would be justified.

Similarly, there is a complete absence of information on the toxic effects of long-term exposure to MTBE of aquatic or other organisms (and only minimal acute toxicity data), even though the concentration at which chronic toxicity occurs is often substantially below that associated with acute effects. The National Research Counsel concluded that the impact of MTBE and other fuel oxygenates on aquatic life is poorly understood (NRC 1996). The NRC states, "Although acute-toxicity assays have been performed on several important species, chronic-toxicity data are lacking. Without chronic-toxicity data, it is not possible to determine whether important aquatic biota might be impaired by exposure to MTBE". Longterm exposure to environmental concentrations of MTBE correspond to the type of exposures typical of those potentially sustained by aquatic organisms, and suggest that studies to characterize chronic effects of MTBE in a variety of aquatic organisms should be given priority.

\section{Terrestrial Organisms}

Terrestrial organisms may appear to have a reduced potential for exposure to MTBE compared to aquatic species due to their terrestrial habitat. However, the exposure analysis for terrestrial organisms is complicated due to the presence of multiple exposure pathways. MTBE present in soil as a result of point-source spills, rain washout or atmospheric deposition can partition into soil-pore water, and thus be available for plant uptake. In addition, plant uptake may occur as a result of atmospheric deposition onto leaf surfaces (McK one and Daniels, 1991). The moderately lipophilic MTBE has the potential to accumulate in plant tissues. There are no data available on the toxicity of MTBE to plants.

Besides the potential for direct impacts to plant populations, MTBE accumulation in plants could be transferred to upper trophic level species through the food chain. As already discussed, there are no data available to assess the potential for food chain transfers of MTBE. In addition, terrestrial wildife could also be exposed to MTBE from soil through direct ingestion. Most food sources for wildlife will have soil residue. In addition, some wildlife species, most notably deer, are known to directly ingest soil (Arthur and Alldredge 1979, Beyer et al. 1991). Wildlife can also directly ingest MTBE through consumption of surface water. 
Finally, wildlife could also be exposed to MTBE through inhalation of both surface and subsurface air. Many terrestrial animals are fossorial (burrowing), and spend a significant amount of time in subsurface burrows. Burrows in areas with MTBE present in the soil could result in significant levels of MTBE in the air of subsurface burrows. Inhalation of contaminated subsurface burrow air can be a significant exposure pathway (Carlsen 1996), and could result in accumulation of MTBE in the exposed animal.

As with aquatic life, data on MTBE toxicity on terrestrial wildlife is lacking. Acute toxicity data on laboratory mammals (most commonly rats and mice) are available (RTI 1994; Broghoff, et al, 1996), and indicate no reproductive or developmental effects. While this suggests the potential for ecological impact on rodents from acute MTBE exposure to be low, no conclusion can be drawn concerning chronic exposures to mammals or other species.

Because of the paucity of data, investigations into the level of exposure of terrestrial plants and animals to MTBE should be conducted. In conjunction, research should be conducted to determine the ability of MTBE to accumulate in and transfer between terrestrial organisms. Finally, studies to characterize the effects of chronic MTBE exposure to a variety of terrestrial organisms should be carried out.

\section{Potential Ecological Endpoints}

An obvious measurement endpoint for the ecological impact of MTBE exposure on both aquatic and terrestrial organisms is impairment of reproduction. This measurement endpoint can be directly related to reductions in populations (an important assessment endpoint)(Spies, et al., 1988a; Spies and Rice, 1988). In aquatic organisms, acute exposure of adults to various exogenous chemicals is defined as those impacts to metabolic systems resulting in death, often within 2-3 days. During chronic exposures, environmental concentrations that may result in no noticeable physical changes in adults may result in reproductive impairment and ultimately in reductions in populations. For MTBE, these reproductive impairments may occur through several mechanisms.

One mechanism is through disruption of endocrine systems. Reproductive dysfunction in wildlife and humans has been linked with increasing frequency to endocrine-disrupting environmental contaminants. Among the endocrine-disrupting chemicals identified to date are a structurally diverse group of substances which bind to the estrogen receptor and elicit estrogen-mediated biological responses. The estrogen receptor, characterized in hepatic and reproductive tissues from a number of species, is closely conserved in vertebrates (Padkel et al. 1992, LeDréan et al. 1995). Chemicals that act via biologically-shared mechanisms of toxicity that affect the reproductive system have 
considerable potential to impact individuals and populations of multiple species. Estrogen agonists and antagonists have in fact been identified as reproductive toxins in a variety of species.

Studies to characterize the binding affinity of MTBE for the estrogen receptor should be initiated as a critical component of any hazard assessment of MTBE. If evidence of estrogen receptor binding is observed, then additional studies are warranted to determine whether the receptor binding is associated with induction or inhibition of transcription of estrogen-responsive genes.

The early life history stages of many species have been shown to be very sensitive to exogenous chemicals. Low environmental concentrations of a variety of compounds have been shown to impair embryogenesis. In aquatic species, developing embryos often utilize lipid yolk as a nutrient source. As an ether, MTBE can be expected to be very lipid soluble. If MTBE or its metabolites are dissolved in egg yolk lipids, they may disrupt the orderly formation of embryonic cells and result in deformed progeny and reduced spawning success.

Dilute concentrations of a recalcitrant lipophilic compound, such as MTBE, may also induce microsomal oxidases that influence hormonal regulation. MTBE itself may not act to induce these isozymes, but metabolic by products such as tert-butyl-alcohol have been shown to be inducers (Broghoff, et al., 1996). In vertebrates, mixed-function oxidase (MFO) enzyme systems regulate steroid concentrations within the body. Some xenobiotic compounds also induce their own metabolism or that of related compounds by stimulating production of MFO enzymes. In this regard, MFO enzymes play a detoxification role.

If an aquatic vertebrate, such as a female fish, is chronically exposed to low concentrations of MTBE during preparation for spawning, internal feed-back mechanisms may be disrupted. During normal spawning, MFO activity is suppressed to allow hormones such as estrogen to accumulate in the body and trigger egg development. If at the same time, exposure to an MFO-inducing MTBE metabolite is occurring, then MFO suppression may not occur. The result is a disruption of egg development and reduced spawning success (Spies, et al, 1988: Spies and Rice, 1988).

\section{Summary of Research Needs}

A multi-disciplinary approach is necessary to adequately assess the potential ecological hazard associated with MTBE exposure. A lead organization should be selected to coordinate the research effort and ensure that the research is conducted in accordance with identified priorities. The lead organization may also conduct a portion of the identified research, but this is not required. Research components should be focused to fill the following data gaps: 
- Better identify and quantify exposure pathways and exposed populations, along with determining actual exposure levels and tissue concentrations (if appropriate) in aquatic and terrestrial organisms

- Determine the ability of MTBE to bioaccumulate/bioconcentrate in aquatic and terrestrial organisms

- Determine the chronic toxicity of MTBE in aquatic and terrestrial organisms, with particular emphasis on reproductive impairment 


\section{References}

Arthur, W. J., III, and A. W. Alldredge. 1979. Soil ingestion by mule deer in N orthcentral Colorado. J. Range Manage. 31(1):67-71.

Beyer, N., E. Conner and S. Gerould. 1991. Survey of soil ingestion by wildlife. Prepared for the U. S. EPA by the U. S. Fish and Wildlife Service and the U. S. Geological Survey, Draft dated March 12, 1991.

Broghoff, S. J., Prescott-Mathews, J. S., and Poet, T. S. 1996. The Mechanism of Male Rat Kidney Tumors Induced by Methyl Tert-Butyl Ether and Its Relevance in Assessing Human Risk. Chemical Industry Institute of Toxicology (CIIT), 16 (10): 8 pp.

Carlsen, T. M. 1996. Ecological Risks to Fossorial Vertebrates from Volatile Organic Compounds in Soil. Risk Analysis 16 (2): 211-219.

Delzer, G. C., Zogorski, J. S., Lopes, T. J., and Bosshart, R. L. 1996. Occurrence of the Gasoline Oxygenate MTBE and BETX Compounds in Urban Stormwater in the United States, 1991 - 95. U.S. Geological Survey Water-Resources I nvestigations Report 96-4145.

Grizzle, J., Horowitz, S. and Strength, D. 1988. Caged Fish as Monitors of Pollution: Effects of Chlorinated Effluent from a Wastewater Treatment Plant. Water Res. Bull., 24: 951-9.

Le Dréan, Y., Kern, L., Pakdel, F., Valotaire, Y. 1995. Rainbow trout estrogen receptor presents an equal specificity but a differential sensitivity for estrogens than human estrogen receptor. Molecular and Cellular Endocrinology (109): 27-35.

Mackay, D. 1991. Multimedia Environmental Models, The Fugacity Approach. Lewis Publishers, Chelsea, Michigan.

McKone, T. E. and J. I. Daniels. 1991. Estimating Human Exposure through Multiple Pathways from Air, Water, and Soil. Reg. Toxicol. Pharm. 13:36-61.

Moriarty, F. 1983. Ecotoxicology: The Study of Pollutants in Ecosystems. Academic Press, New York, N.Y.

National Research Council (NRC). 1996. Toxicological and Performance Aspects of Oxygenated Motor Fuels. National Academy Press, Washington, D. C.

Office of Science and Technology Policy (OSTP). 1996. Fue Oxygenates and Water Quality: Current Understanding of Sources, Occurrence in Natural Waters, Environmental Behavior, Fate, and Significance. 
Interagency Oxygenated Fuel Assessment, Office of Science and Technology Policy, March 1996.

Pakdel, F., Katzenellenbogen, B. L. 1992. Human estrogen receptor mutants with altered estrogen and antiestrogen ligand discrimination. J . of Biological Chemistry (267)5: 3429-3437.

Research Triangle Institute (RTI). 1994. Toxicological Profile for Methyl tert-Butyl Ether. Prepared for the U. S. Department of Health and Human Services, Public Health Service, Agency for Toxic Substances and Disease Registry under Contract No. 205-93-0606.

Rice, D. W., Seltenrich, C. P., Keller, M. L., Spies, R. B., and Felton, J. S. 1994. Mixed-Function Oxidase-Specific Activity in Wild and Caged Speckled Sanddabs, Citharichthys stigmaeus, in Elkhorn Slough, Moss Landing Harbor and Nearshore Monterey Bay, California. Environ. Pollut., 84: 179-188.

Solomon, K. R. 1996. Overview of Recent Developments in Ecotoxicological Risk Assessment. Risk Analysis 16(5): 627-633.

Spies, R. B., and Rice, D. W., J r. 1988. Effects of Organic Contaminants on the Reproduction of the Starry Flounder, Platichthys stellatus, in the San Francisco Bay. II. Reproductive Success of Fish Captured in San Francisco Bay and Spawned in the Laboratory. Marine Biology. 98: 191200.

Spies, R. B., Rice, D. W., J r., and Felton, J. 1988. Effects of Organic Contaminants on the Reproduction of the Starry Flounder, Platichthys stellatus, in the San Francisco Bay. I. Hepatic Contamination and mixed-function Oxidase (MFO) Activity During the Reproductive Season. Marine Biology. 98: 181-189.

Squillace, P. J., Pankow, J. F., Korte, N. E., and Zogorski, J. S. 1996. Environmental Behavior and Fate of Methyl Tert-butyl Ether (MTBE). U.S. Geological Survey Fact Sheet, FS-203-96.

Suter II, G. W. 1990. Endpoints for Regional Ecological Risk Assessment. Environmental Management 14(1): 19-23.

Suter, G., Rosen, A., Linder, E., and Parkhurst, D. 1987. End-points for Responses of Fish to Chronic Toxic Exposures. Environ. Toxicol. Chem., 6: 793-809.

Suter, G. W. II and J. M. Loar. 1992. Weighing the Ecological Risks of Hazardous waste sites: The Oak Ridge Case. Environ. Sci. Technology 26(3): 432-438. 
U. S. Environmental Protection Agency (USEPA). 1992. Framework for Ecological Risk Assessment. EPA/630/R-92/001. U. S. Environmental Protection Agency, Washington, D. C.

Warren-Hicks, W., Parkhurst, G. R., and Baker, S. S., J r., Eds. 1989. Ecological assessment of Hazardous Waste Sites: A Field and Laboratory Reference Document. EPA/600/3-89/013. U. S. Environmental Protection Agency, Washington, D. C. 


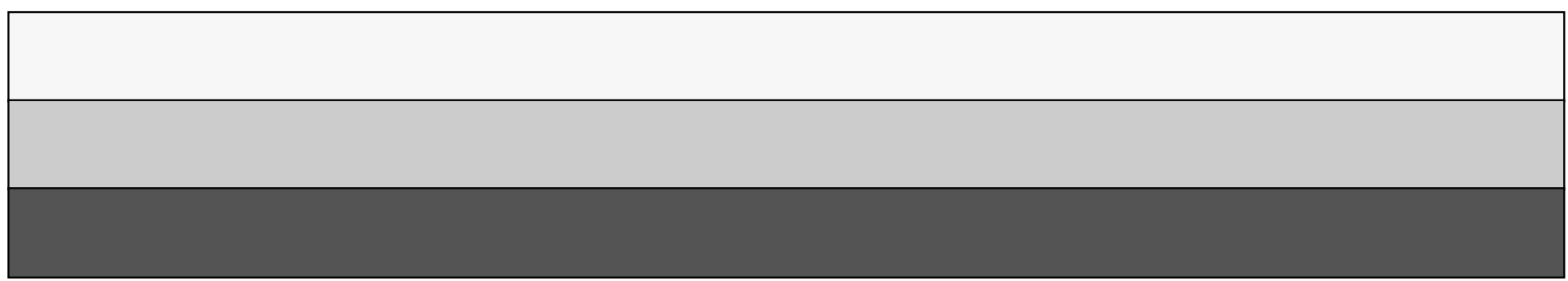

